\title{
DEFORMATION AND ENERGY PARAMETERS OF FRACTURE OF STEEL OF THE MAIN GAS PIPELINE
}

\author{
Pavlo Maruschak', Sergey Panin², Ulyana Polyvana' ${ }^{1}$, Tomaž Vuherer³ \\ Anna Guzanová4, Janette Brezinová4 \\ 1 Ternopil Ivan Pul'uj National Technical University, 56 Ruska Str., Ternopil 46001, Ukraine, e-mail: Maruschak. \\ tu.edu@gmail.com \\ 2 Institute of Strength Physics and Materials Science SB RAS, 2/4 pr. 2 Akademicheskii, Tomsk 634021, Russia \\ 3 Faculty of Mechanical Engineering, University of Maribor, Smetanova 17, 2000 Maribor, Slovenia \\ 4 Technical University of Košice, Department of Technology and Materials, Košice, Slovakia
}

Received: 2015.10.09

Accepted: 2015.11.14

Published: 2015.12.04

\begin{abstract}
By example of steel $17 \mathrm{G} 1 \mathrm{~S}$, the regularities in the impact fracture of Charpy specimens at normal and low temperatures are described. The relationship between the energy parameters of fracture (impact toughness) and the deformation response of the material (the height of shear lips) of the specimens from the pipe steel is established. The micromechanisms of impact fracture of the material are described. At $20^{\circ} \mathrm{C}$ and $-30{ }^{\circ} \mathrm{C}$, focal splitting of the material was observed on the fracture surface of specimens; at $-60^{\circ} \mathrm{C}$, the material failed in a brittle manner by the mechanism of cleavage.
\end{abstract}

Keywords: impact toughness, main gas pipeline, failure analysis.

\section{INTRODUCTION}

Gas transportation system of Ukraine is the second largest in Europe and one of the largest in the world. It consists of a number of main gas pipelines with the total length of 37.6 thousand $\mathrm{km}$ (single-stranded calculation), 71 compressor stations (122 compressor shops), and 13 underground storage facilities. However, the vast majority of gas pipelines of this system have been operated for 30-40 years [1-3]. This makes it necessary to increase the reliability of their operation, based on the account of the actual condition of the objects.

It is known that the most objective method of assessing the quality of the pipe is pneumatic field tests, however, to assess the condition of the main gas pipelines in operation, laboratory techniques and methods of nondestructive testing are usually used [4-6]. This creates prerequisites for finding new fracture toughness criteria under various types of loading, determining the physical laws of degradation of pipe materials after a long-term operation, taking into account the effect of the maximum number of in-service factors. Particular attention is paid to the exhaustion of steel plasticity, hydrogenation, the analysis of the impact of these degradation processes on the microstructural changes $[7,8]$.

The reason for an unpredictable destruction of the main gas pipelines, as a rule, is the availability of stress concentrators of the mechanical origin (scratches, technological defects), as well as corrosion damage [9]. All of these reasons for failure are well studied. A significant number of non-destructive methods are developed, which allow determining the structural changes in the pipeline metal and localization of defects. At the same time, one of the most informative characteristics of the mechanical properties of the pipe metal is fracture toughness that allows for the express diagnostics of the influence of the operational factors on the load-bearing capacity and structural condition of the material [10].

However, the comprehensive use of this test method requires using the methods of physical 
mesomechanics and considering the process of deformation and destruction of the material as a phasic event with characteristic phases [11]. A number of studies are known, in which the mechanisms of damage accumulation are described, and changes in the mechanical characteristics of strength and ductility of the pipe steel are identified using a phenomenological approach $[12,13]$. In these studies, using the energy approach of fracture mechanics, the indicators of energy intensity of the nucleation and propagation of cracks in view of the microstructure and scale levels of the deformation process are obtained. That is why the identification of the relationship between the localized and integral parameters of the fracture surface condition and the energy intensity of their destruction is an important and urgent task. Some articles are known [14, 15], which proposed to use the height of shear lips as a deformation criterion of fracture toughness of the material in case of impact fracture [9]. This approach is similar to the approaches of nonlinear fracture mechanics, which use the parameters of the crack tip opening and the angle of its opening.

The purpose of this article is to study fracture toughness of the main gas pipeline material, using energy and deformation parameters.

\section{METHODS}

Fracture toughness was measured on specimens of $10 \times 10 \times 55 \mathrm{~mm}$ with a V-notch and the radius of $0.25 \pm 0.025 \mathrm{~mm}$. Tests were carried out on the impact testing machine RKP-300 with the impact energy of $300 \mathrm{~J}$. The scheme of cutting and the form of Charpy specimens for impact tests were selected from the simulation of crack propagation in the pipe of the main gas pipeline (Fig. 1). During operation of the main pipeline,

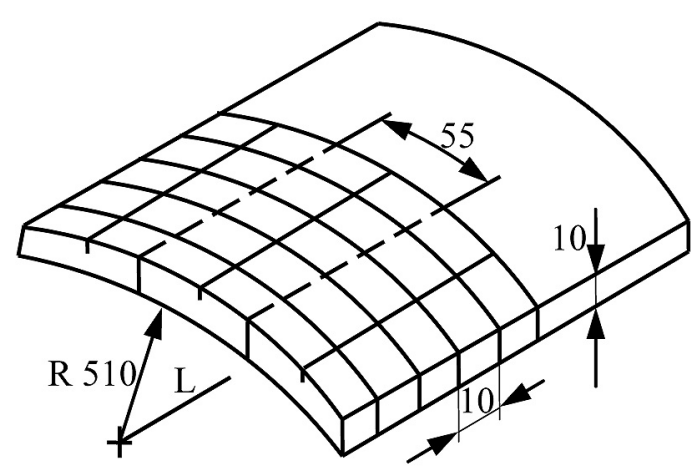

Fig. 1. Schemes of cutting Charpy specimens from a fragment of the main gas pipeline cracks are usually generated on the surface and propagate in the radial direction.

Fracture toughness was determined from the formula:

$$
K C V=A / F
$$

where: $A$ is the work to failure; $F$ is the crosssectional area of the specimen in the place of the notch.

\section{RESULTS}

Ferrite and pearlite grains were found within the structure of steel $17 \mathrm{G} 1 \mathrm{~S}$. The structure of the pipe cross section was somewhat different. In particular, a certain reduction in the pearlite component was observed near the outer surface of the pipe. In our opinion, this is due to the technological peculiarities of rolling of the pipe metal, in particular, eventual decarbonization. Some defects were revealed, which might impair the mechanical properties of the material (Fig. 2).

The effect of lowering the test temperature on the impact toughness of steel 17G1S was analyzed. It was revealed that, compared with the fracture energy at $20{ }^{\circ} \mathrm{C}$, the fracture energy at $-30{ }^{\circ} \mathrm{C}$ decreases by 1.2 times, and at $-60^{\circ} \mathrm{C}-$ by 3.0 times (Table 1 ).

\section{Shear lips}

It is known that the first plastic deformation zones are formed near the tip of the concentrator (a notch) [18-20]. Their advancement in the volume of the material leads to the activation of shear displacement of grains in the elastically-plastically deformed portions of the specimen material. An elementary act of plastic yielding in this case is "shift + turn" [19]. This mechanism is due to the accommodation of local strains in the material sections. It involves not only individual grains, but their conglomerates, causing deformational instability of the adjacent sections. It should be noted that such a dynamic adaptation of the material under the dynamic impact is a consequence of a self-organization of the polycrystalline material. At the same time, there is a self-organization of the structural-mechanical levels of deformation of local sections of the material into the energetically most favorable configuration under given loading conditions [20]. Increasingly large conglomerates of grains become involved in the deformation process, and deformational fragmentation of the 
Table 1. Impact toughness of the main gas pipeline material at different test temperatures

\begin{tabular}{|c|c|c|c|}
\hline \multirow{2}{*}{ Impact toughness of steel 17G1S } & \multicolumn{3}{|c|}{ Temperature test, ${ }^{\circ} \mathrm{C}$} \\
\cline { 2 - 4 } & 20 & -30 & -60 \\
\hline $\mathrm{MJ} / \mathrm{m}^{2}$ & 0.45 & 0.38 & 0.15 \\
\hline
\end{tabular}

a)

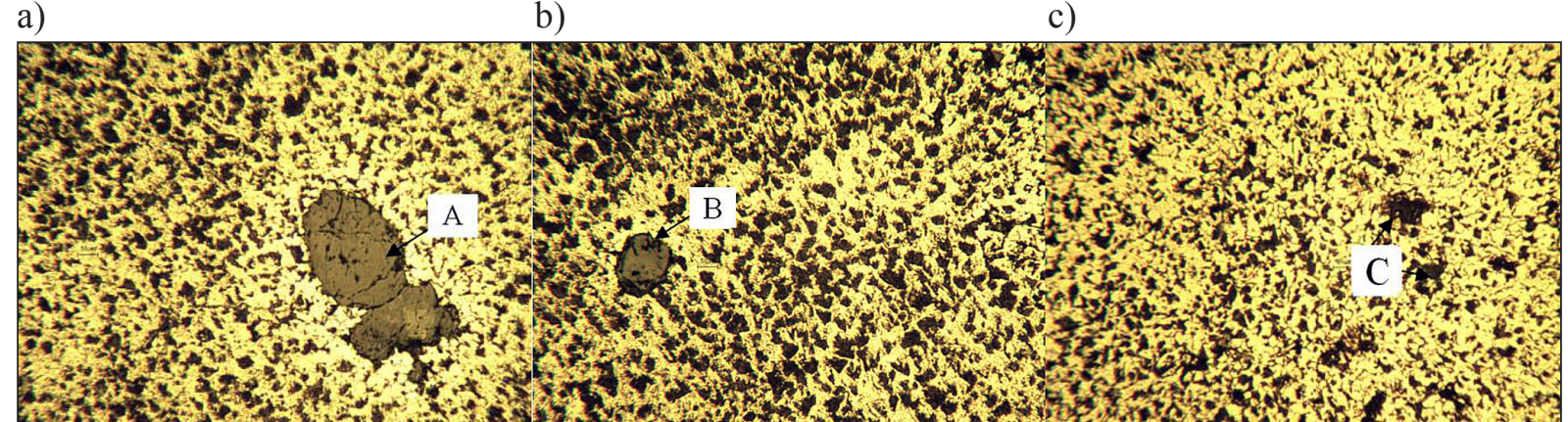

Fig. 2. Microstructure of the main gas pipeline $(\times 200): \mathrm{a}, \mathrm{b}-$ inner wall of the pipe; $\mathrm{c}-$ outer wall of the pipe; A-C - structural defects

material occurs at the meso-level [19, 20]. Failure of the material is the final stage of fragmentation, when the process transfers to the macro-level, followed by a global loss of shear stability. Shear lips are the final result of adaptation of the local portion of the material to the conditions of deformation and subsequent failure. The parameters of shear lips are the informative signs that evaluate the energy intensity of the dynamic failure of materials. The parameters considered in this paper are $h_{\text {pos }}-$ the height of shear lips [14] and $h_{\text {neg }}-$ the depth of tears-out (Fig. 3).

High speed of impact loading and dynamic effects exerted on the material leads to the situation when the mechanisms of relaxation and redistribution of strains are not fully implemented during deformation [20]. In addition, the temperature-force conditions of loading have a determining influence on the fracture toughness of metal. A decrease in the test temperature leads to a change in the stress-strain state of the material, which is most pronounced in the near sur-

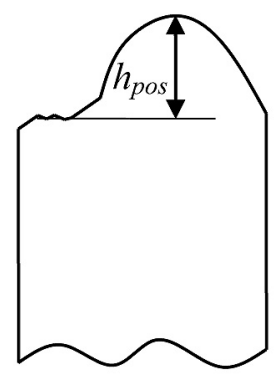

a

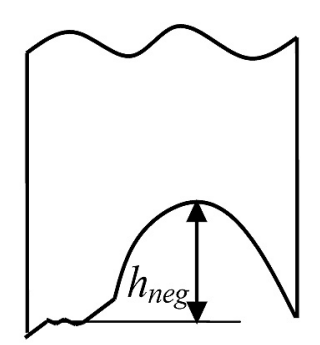

b
Fig. 3. Scheme of measurement: $a, b$ - images of shear lips and tears-out on the surface of Charpy specimens; $\mathrm{h}_{\text {pos }}-$ the height of shear lips; $\mathrm{h}_{\text {neg }}-$ the depth of tears-out face layers and is depicted in the parameters of shear lips. A reduction in the test temperature from $20^{\circ} \mathrm{C}$ to $-60^{\circ} \mathrm{C}$ leads to a decrease in the rate of rotation of meso-fragments (grain conglomerates), and promotes the formation of the crack in the vicinity of the macroconcentrator, thus reducing the energy intensity of fracture [17].

\section{Effect of temperature}

It is known that the dynamic force effect on the material may result in a substantial gradient of strain distribution in its structural elements. Deformation processes at the meso-level are implemented in two-dimensional structural formations, i.e. shear lips. The parameters and shape of the fragments involved in the deformation process depict the energy intensity of deformation parameters of the material and its fracture toughness. At $20{ }^{\circ} \mathrm{C}$, significant deformational manifestations were observed, the height of shear lips / the depth of tears-out was $2.1 / 0.75 \mathrm{~mm}$, at $-30^{\circ} \mathrm{C}$, the same parameters were $2.0 / 7.0 \mathrm{~mm}$, but at $-60^{\circ} \mathrm{C}$, they were concentrated in local areas, which is depicted, in particular, in a reduction of the height of shear lips to $0.70-0.25 \mathrm{~mm}$, which correlates with the energy intensity of failure (Fig. 4).

It is known that fracture energy of the metal under impact loading depends on its ductility and is proportional to the deformed volume of the specimen [6]. Plastic material has higher values of volume deformation and the highest energy intensity of failure (Fig. 4).

To account for the difference between the height of shear lips $\left(\mathrm{h}_{\mathrm{pos}}\right)$ and the depth of the rel- 


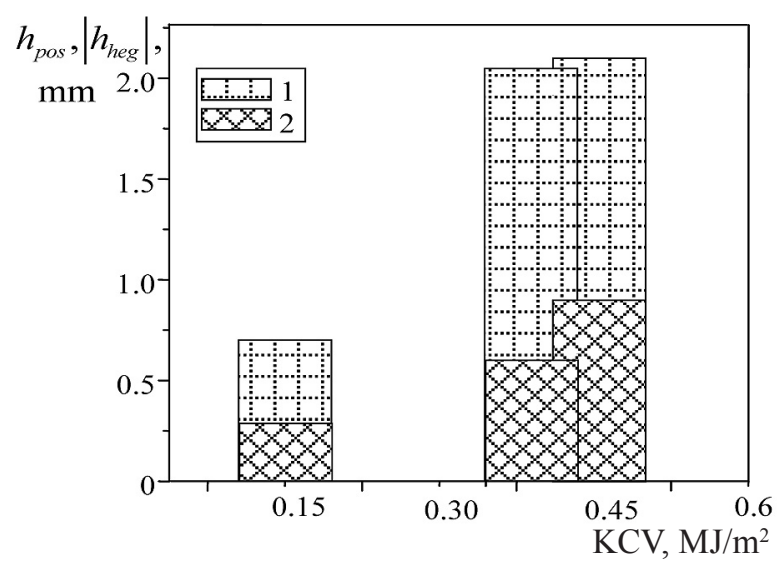

Fig. 4. Dependence of fracture toughness of Charpy specimens from steel $17 \mathrm{G} 1 \mathrm{~S}$ on the height of shear lips $h_{p o s}(1)$ and the depth of surface tears-out $\left|h_{\text {neg }}\right|$ (2)

evant tear-out $\left(\mathrm{h}_{\text {neg }}\right)$, the relative measure $\lambda$ was introduced. Since the sign "-“" (typical of measuring the depth of tears-out) characterizes only the direction of the geometrical heterogeneity of the relief relative to the notch, we took into account the absolute value of this measure:

$$
\lambda=\left[h_{\text {pos }}-\left|h_{\text {neg }}\right|\right] / h_{\text {pos }}
$$

Ideally, the above parameters are equal $\left(\mathrm{h}_{\text {neg }}\right.$ $=\mathrm{h}_{\mathrm{pos}}$ ), but since the formation of tears-out is a stochastic process, the depth of surface tears-out typically has a lower value. This is due to the peculiarities of its measurement and the gradient of the parameter values across the width of a shear lip. The authors obtained the dependence of this parameter on the test temperature of Charpy specimens from steel 17G1S (Fig. 5).

Parameter $\lambda$ takes the value in the range from 0.57 to 0.71 . In our opinion, this reflects a change in the surface condition and an increase in heterogeneity of the processes of deformation and fracture, which involve large volumes of the material.

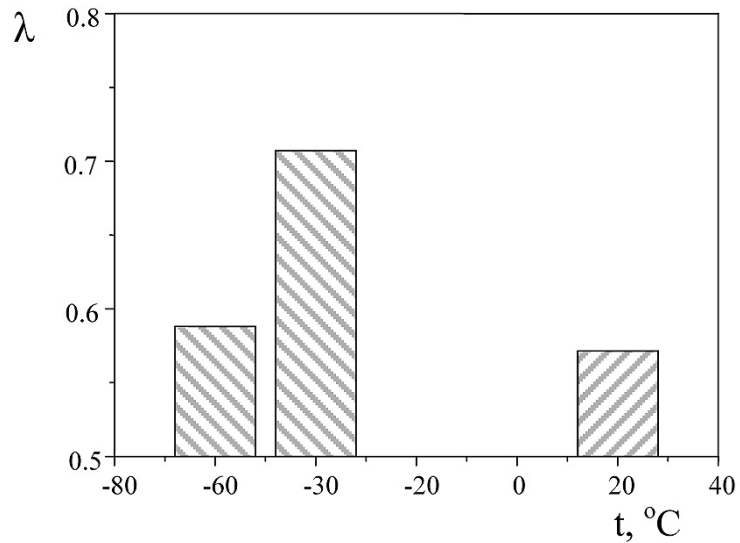

Fig. 5. Dependence of $\lambda$ on the test temperature of Charpy specimens

\section{Fracture surface}

Hierarchical processes of deformation and fracture are conventionally divided in fracture mechanics into the initiation and propagation of a crack in Charpy specimens and depend significantly on the self-organization of the material at the micro- and meso- levels, since at these levels a significant energy dissipation may occur, which leads to the formation of fracture planes, branching and micro-plastic deformation [21-23] (Fig. 6a-c). As has been proved above, the surface roughness of specimens caused by deformation and fracture of the material - i.e. shear lips, reflects the kinetics of failure and the stress-strain state of specimens. The shape of shear lips characterizes the energy intensity of fracture and can be considered as a parameter of fracture toughness of the material.

Let us consider the profiles of fracture surfaces of Charpy specimens obtained during tests at different temperatures (Fig. 6a-f):

- $20{ }^{\circ}$ C. Rounded shear lips are wave-like morphological formations on the surface of the material, which are formed by vertical and horizontal deformation processes (Fig. 6a). The shape of shear lips at $20{ }^{\circ} \mathrm{C}$ is "undulating" and rather simple. The fracture surface at the micro-level has a banded appearance. Bands (organized tears-out of the material) are oriented perpendicular to the direction of the cracks growth, which, in our opinion, causes braking of the crack front in some areas of the crack growth. The bands have a viscous appearance and are covered with large rounded pits, which is a further evidence of ductile fracture (Fig. 6d). The microrelief is formed by a ductile-brittle mechanism, the pits have a rounded, and in some area semi-elliptical shape, their size is in the range of 5-10 $\mu \mathrm{m}$. They are trimmed with viscous ridges formed as a result of plastic deformation that precedes fracture of plastically deformed pores.

- $-30{ }^{\circ} \mathrm{C}$. Shear lips with tears-out were observed on the surface of specimens with significant surface discontinuities. Surface discontinuities were formed mainly by deformation processes of separation and shear (Fig. 6b). At the micro-level, the mechanism of fracture has a quasi-brittle appearance, although at the macro-level, the "banded" pattern of the front of destruction is maintained. In addition, the bands become narrower and shorter. Certain 


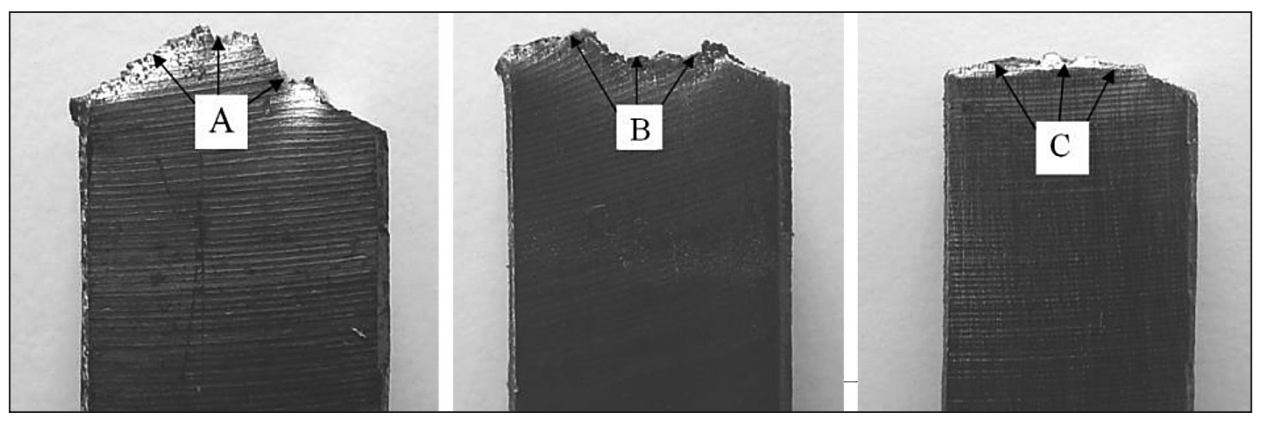

a)

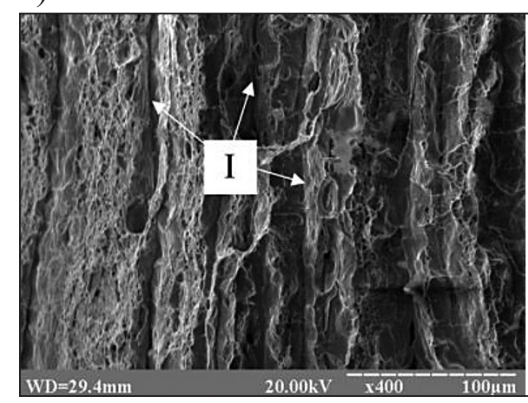

b)

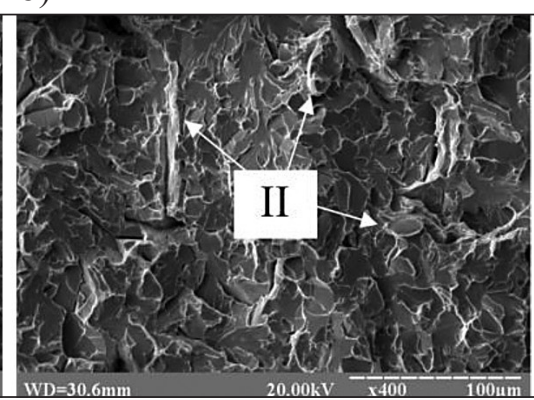

c)

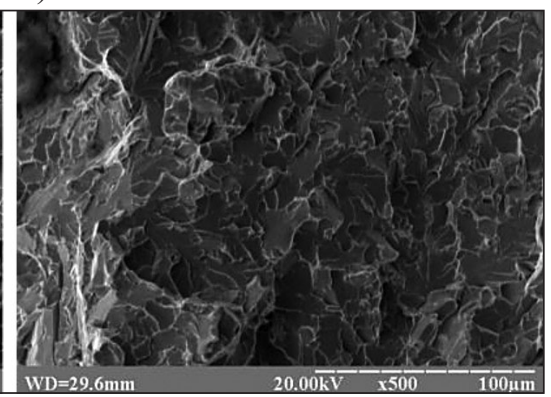

Fig. 6. Micromechanisms of fracture of steel $17 \mathrm{G} 1 \mathrm{~S}$ at $20^{\circ} \mathrm{C}(\mathrm{a}, \mathrm{b}),-30^{\circ} \mathrm{C}(\mathrm{c}, \mathrm{d})$, and $-60{ }^{\circ} \mathrm{C}(\mathrm{e}, \mathrm{f})$ : $\mathrm{A}-$ rounded shear lips; B - shear lips with tears-out; C - degenerate shear lips; I - "banded" fracture; II - quasi-brittle cleavage

parts of the crack front are formed by cleavage. Fracture surface has a brittle view and is trimmed with a multitude of micropits of $2-3$ $\mu \mathrm{m}$ (Fig. 6c). The pits are not deep, of about the same size, with sharp crests located in one plane. "Flat" structureless areas were found between the pits.

- $-60{ }^{\circ} \mathrm{C}$. Degenerate shear lips with a small height, indicating a low energy intensity of fracture, are typical of the low test temperature (Fig. 6c). Their surface is divided by narrow zones of local tears-out of the material. The specimen fracture has a brittle view (Fig. 6e). The surface acquires a "smoothed-out view", contractions are absent, shear lips have a degenerate view.

\section{DISCUSSION}

Previously it was found that under the operating conditions, as a result of a prolonged contact between the pipe and corrosive environment, which leads to the electrolytic corrosion, hydrogenation of the pipeline wall occurs $[24,25]$. The phenomenon of embrittlement and accumulation of scattered structural defects is a consequence of the synergistic effect of operating stresses, corrosion processes and hydrogen on the material. This leads to the accumulation and consolidation of dislocations, reduction in their mobility, increase in microstrains and subsequent formation of defects, which are a trap for further accumulation of hydrogen [2].

Let us generalize the regularities in deformation and fracture of the gas pipeline material (steel 17G1S) at different structural levels. The energy intensity of fracture depends not only on the size of the specimen fracture surface, but on the hardness of the stress-strain state of the material volumes in these areas [16]. Moreover, while at the macroscale level the deformed material undergoes shear deformation and detachment, and at the mesolevel - shear and turn, at the microlevel it undergoes shear, turn and local extension.

A peculiarity of the specimen fracture is the presence of multiple laminations in the plane of propagation of macrofracture (Fig. 7a, b). These defects result from the laminated structure of specimens, which resembles a composite [21, 22], moreover, the crack propagates between its "fibers", i.e., in a particular plane. If the crack front deviates from this plane and "jumps" to an adjacent plane, a local change in strains occurs in the limited area, where surface separation or tearout takes place. This leads to a situation when fracture surface becomes covered with curvilinear sections of the turn of the crack front. Thus, the production technology of pipes and the resulting "banded" structure to a certain extent prevents macrofracture at $20{ }^{\circ} \mathrm{C}$ and partly at $-30{ }^{\circ} \mathrm{C}$. At $-60{ }^{\circ} \mathrm{C}$, this effect is completely suppressed, and fracture is brittle. 
a)

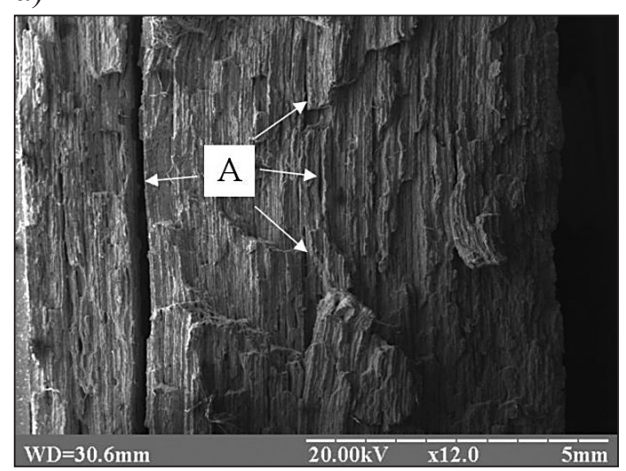

b)

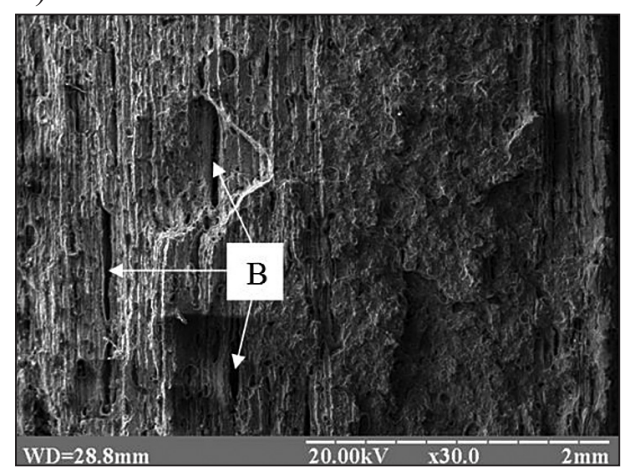

Fig. 7. Laminations on the fracture surface of steel $17 \mathrm{G} 1 \mathrm{~S}$ at $20^{\circ} \mathrm{C}$ (a) and $-30{ }^{\circ} \mathrm{C} \mathrm{(b):}$

$\mathrm{A}$ - mechanical laminations; $\mathrm{B}$ - hydrogen laminations

It is proved that the energy intensity of fracture is closely associated with the relief elements of the destroyed specimens. Shear lips are used as the strain parameter of nonlinear fracture mechanics, which depicts the accumulation of localized strains in the specimen material, formation of the accommodative strain domains in the material volume, and the mechanisms of crack branching through the plastically deformed sections of the material $[19,20]$. A decrease in the plasticity of steel $17 \mathrm{G} 1 \mathrm{~S}$ at low temperatures reduces the possibilities of implementing the mechanisms of turn and stress relaxation during crack propagation (Table 2). This causes low values of the energy intensity of fracture (macro-level) and brittle cleavage of the material (microlevel), which is most pronounced in the parameters of shear lips.

The results obtained by the authors assist in improving the validity of monitoring the condition of the gas pipeline material, since they show the relationship between the structure, fracture toughness and deformation parameters of the material [14-17]. In our opinion, they can be an effective supplement to the non-destructive control methods. Studying the properties of the gas pipeline metal and the objectiveness of the reliability assessment of the working systems during their maintenance will ensure safety of their operation.

\section{CONCLUSIONS}

The regularities in deformation and fracture of specimens from steel $17 \mathrm{G} 1 \mathrm{~S}$ of the main gas pipeline "Kyiv-West 1 " after 40 years of operation are established. It is proved that the fracture energy of specimens is associated with the manifestations of the deformation process at the meso-level -i.e. the height of shear lips and the depth of corresponding tears-out. At $20^{\circ} \mathrm{C}$, the fracture toughness of specimens was $\mathrm{KCV}=0,45 \mathrm{MJ} / \mathrm{m}^{2}$, the height of shear lips / the depth of tears-out was $2.1 / 0.75 \mathrm{~mm}$, at $-30{ }^{\circ} \mathrm{C}$, the fracture toughness of specimens was $\mathrm{KCV}=0,38 \mathrm{MJ} / \mathrm{m}^{2}$, the height of shear lips / the depth of tears-out was $2.0 / 7.0 \mathrm{~mm}$, but at $-60^{\circ} \mathrm{C}$, they were concentrated in local areas, which is depicted, in particular, in a reduction in the height of shear lips to $0.70-0.25 \mathrm{~mm}$, and $\mathrm{KCV}=0.15 \mathrm{MJ} / \mathrm{m}^{2}$.

A long-term operation led to the hydrogenation of the pipe wall and local laminations of the material, which are most pronounced at $20^{\circ} \mathrm{C}$ and $-30^{\circ} \mathrm{C}$ - the fracture mechanism is ductile-brittle. At $-60^{\circ} \mathrm{C}$, the fracture surface of the material is formed by the mechanism of brittle cleavage.

The obtained patterns of degradation and impact fracture of steel $17 \mathrm{G} 1 \mathrm{~S}$ can be used to analyze the cases of premature brittle fracture and to diagnose other oil and gas pipelines from steels of this class.

Table 2. Mechanisms of deformation and fracture of Charpy specimens from steel 17G1S

\begin{tabular}{|l|l|l|l|}
\hline \multirow{2}{*}{ Scale level, parameter } & \multicolumn{3}{|c|}{ Mechanisms of deformation process at various test temperatures, ${ }^{\circ} \mathrm{C}$} \\
\cline { 2 - 4 } & \multicolumn{1}{|c|}{-60} & \multicolumn{1}{|c|}{-30} \\
\hline $\begin{array}{l}\text { Specimen fracture surface } \\
\text { (macrolevel) }\end{array}$ & $\begin{array}{l}\text { Brittle fracture by means of } \\
\text { cleavage }\end{array}$ & $\begin{array}{l}\text { Mitigated manifestations of ductile } \\
\text { fracture, heterogeneous tears-out } \\
\text { and bands, which alternate with } \\
\text { the sites of cleavage }\end{array}$ & $\begin{array}{l}\text { Inhomogeneous ductile defor- } \\
\text { math with the formation of } \\
\text { tears-out and bands }\end{array}$ \\
\hline $\begin{array}{l}\text { Relief of shear lips } \\
\text { (mesolevel) }\end{array}$ & $\begin{array}{l}\text { Degenerate (flat) shear lips, } \\
\text { indicating a low energy intensity } \\
\text { of the material fracture }\end{array}$ & $\begin{array}{l}\text { Inhomogeneous formation of } \\
\text { shear lips, multiple tears-out of the } \\
\text { metal, crack branching. }\end{array}$ & $\begin{array}{l}\text { Well-developed rounded } \\
\text { shape }\end{array}$ \\
\hline $\begin{array}{l}\text { Local cleavage in individual } \\
\text { grains (microlevel) }\end{array}$ & $\begin{array}{l}\text { Fracture by means of brittle } \\
\text { cleavage }\end{array}$ & $\begin{array}{l}\text { Brittle fracture + separation } \\
\text { micropits }\end{array}$ & Ductile pit fracture \\
\hline
\end{tabular}




\section{Acknowledgements}

This work was supported by the Slovak Research and Development Agency under the contract No. SK-UA-2013-0013.

\section{REFERENCES}

1. Gabetta G., Nykyforchyn H.M., Lunarska E., Zonta P.P., Tsyrulnyk O.T., Nikiforov K., Hredil M.I., Petryna D.Yu., Vuherer T.: In-service degradation of gas trunk pipeline X52 steel. Materials Science, 44 (1), 2008, 104-119.

2. Nykyforchyn H., Lunarska E., Tsyrulnyk O.T., Nikiforov K., Genarro M.E., Gabetta G.: Environmentally assisted "in-bulk" steel degradation of long term service gas trunkline. Engineering Failure Analysis, 17(3), 2010, 624-632.

3. Banahevych Yu.V., Andreikiv O.E., Kit M.B.: Prediction of residual pipeline recourse taking into account the operation loading conditions. Strength of Materials, 397(1), 2009, 44-52.

4. Nykyforchyn H., Lunarska E., Tsyrulnyk O., Nikiforov K., Gabetta G.: Effect of the long-term service of the gas pipeline on the properties of the ferrite-pearlite steel. Materials and Corrosion, 60, 2009, 716-725.

5. Kryzhanivs'kyi E.I., Nykyforchyn H.M.: Specific features of hydrogen-induced corrosion degradation of steels of gas and oil pipelines and oil storage reservoirs. Materials Science, 47(2), 2011, 127-136.

6. Tsyrul'nyk O.T.: Application of the electrochemical methods in the diagnostics of the engineering state of structural materials. Materials Science, 49(4), 2014, 449-460.

7. Marushchak P.O., Salo U.V., Bishchak R.T., Poberezhnyi L.Ya.: Study of main gas pipeline steel strain hardening after prolonged operation. Chemical and Petroleum Engineering, 50(1-2), 2014, 58-61.

8. Konovalenko I.V., Marushchak P.O., Danilyuk I.M.: Fractographic and defect measurement analysis of multiple pitting corrosion parameters. Chemical and Petroleum Engineering, 50(7-8), 2014, 457-463.

9. Kim J.-H., Choi S.-W., Park D.-H., Lee J.-M.: Charpy impact properties of stainless steel weldment in liquefied natural gas pipelines: Effect of low temperatures. Materials \& Design, 65, 2015, 914-922.

10. Panin V.E., Pleshanov V.S., Kobzeva S.A., Burkova S.P.: Relaxation mechanism of rotational type in fracture of weld joints for austenic steels. Theoretical and Applied Fracture Mechanics, 29(2), 1998, 99-102.

11. Richards F.: Failure Analysis of a natural gas pipeline rupture. Journal of Failure Analysis and Prevention, 13(6), 2013, 653-657.

12. Verdeja J.I., Asensio J., Pero-Sanz J.A.: Texture, formability, lamellar tearing and HIC susceptibility of ferritic and low carbon steels. Materials Characterization, 50, 2003, 81-86.

13. Yamamoto I., Mukaiyama T., Yamashita K., Sund Z.M.: Effect of loading rate on absorbed energy and fracture surface deformation in a 6061-T651 aluminum alloy. Engineering Fracture Mechanics, 71(9-10), 2004, 1255-1271.

14. Shterenlikht A., Howard I.C.: Partition of Charpy fracture surface with digital image processing. International Journal of Fracture, 129(1), 2004, 39-50.

15. Maruschak P.O., Bishchak R.T., Vuherer T.: Laws governing the dynamic fracture of two-layer bimetallic composites. Metallurgist, 55(5-6), 2011, 444-449.

16. Maruschak P.O., Danyliuk I.M., Bishchak R.T., Vuherer T.: Low temperature impact toughness of the main gas pipeline steel after long-term degradation. Central European Journal of Engineering, 4(4), 2014, 408-441.

17. Makarov P.V.: Localized deformation and fracture of polycrystals at mesolevel. Theor. Appl. Fracture Mech., 33(1), 2000, 23-30.

18. Balokhonov R.R., Stefanov Yu.P., Makarov P.V., Smolin I.Yu.: Deformation and fracture of surfacehardened materials at meso- and macroscale levels. Theor. Appl. Fracture Mech., 33(1), 2000, 9-20.

19. Romanova V., Balokhonov R., Makarov P., Schmauder S., Soppa E.: Simulation of elasto-plastic behaviour of an artificial 3D-structure under dynamic loading. Computational Materials Science, 28 (3-4 spec. iss.), 2003, 518-528.

20. Goritskii V.M., Shneyderov G.R., Lushkin M.A.: Nature of anisotropy of impact toughness of structural steels with ferrite-pearlite structure. The Physics of Metals and Metallography, 114(10), 2013, 877-883.

21. Joo M.S., Suh D.W., Bae J.H, Bhadeshia H.K.D.H.: Role of delamination and crystallography on anisotropy of Charpy toughness in API-X80 steel. Materials Science and Engineering A, 546, 2012, 314-322.

22. Balokhonov R., Romanova V., Schmauder S.: Numerical simulation of intermittent yielding at the macro and mesolevels. Computational Materials Science, 32(3-4), 2005, 261-267.

23. Maruschak P., Bishchak R., Konovalenko I., Menou A., Brezinová J.: Effect of long term operation on degradation of material of main gas pipelines. Materials Science Forum, 782, 2014, 279-283.

24. Fassina P., Bolzoni F., Fumagalli G., Lazzari L., Vergani L., Sciuccati A.: Influence of hydrogen and low temperature on mechanical behaviour of two pipeline steels. Engineering Fracture Mechanics, 81, 2012, 43-55. 